\title{
Comportamento do regime pluviométrico no município de Catolé do Rocha no Estado da Paraíba, Brasil
}

\section{Behavior of the rainfall regime in municipality of Catole do Rocha in the state of Paraíba, Brazil}

\author{
José Geraldo Araújo Ferreira Filho ${ }^{1}$, Tainara Tâmara Santiago Silva ${ }^{2}$, Hallyson Oliveira ${ }^{3}$, Danilo Rodrigues Monteiro ${ }^{4}$, \\ Soahd Arruda Rached Farias ${ }^{4}$
}

\begin{abstract}
Resumo: A região semiárida do nordeste lida periodicamente com chuvas irregulares em todo seu território, comprometendo o desenvolvimento da região. O objetivo deste trabalho é avaliar o regime de chuvas no município de Catolé do Rocha, identificar se a precipitação pluviométrica é suficiente para suprir as necessidades da população e apresentar formas para um bom aproveitamento e manejo da água de chuva. A área em estudo está localizada no estado da Paraíba, no município de Catolé do Rocha.O procedimento metodológico consistiu da análise de um banco de dados referentes aos últimos 17 anos, relacionados à precipitação do município de Catolé do Rocha, sendo estes dados oriundos da Agência Executiva de Gestão das Águas do Estado da Paraíba. A partir dos dados observados foi possível realizar uma análise estatística descritiva com valores de média, mediana, coeficiente de variação, máximo e mínimo, além de confrontar as demandas de água necessárias para suprir as pessoas e animais de produção do local. Os dados estimados para consumo humano e animal, foram ajustados de vários comunicados técnicos do IBGE. Após análise dos dados, observou-se que o município de Catolé do Rocha apresentou uma precipitação média anual de794,5mm e que em dez anos desta sequência, os valores apresentados foram inferiores a média. As técnicas e obras que minimizem o efeito de evaporação dos mananciais e solo, associado a captações de água superficiais são caminhos para um desenvolvimento econômico e com visão sustentável.
\end{abstract}

Palavras-chave: água, desenvolvimento econômico, visão sustentável.

Abstract: The semiarid region of northeast deals regularly with irregular rainfall throughout its territory, compromising the development of the region. The objective of this study is to evaluate the rainfall in the municipality of the Catole do Rocha, identify if the rainfall is sufficient to meet the needs of the population and present ways to a good use and management of rainwater. The study area is located in the state of Paraiba, in the municipality of Catole do Rocha. The methodological procedure consisted of the analysis of a database for the last 17 years, related to precipitation in the municipality of Catolé do Rocha, and these data from the Executive Management Agency Waters of the State of Paraíba. From the observed data was possible to carry out a descriptive statistical analysis with mean values, median, coefficient of variation, maximum and minimum, and confront the water demands necessary to meet the people and the local production of animals. The estimated data for human and animal consumption were adjusted several technical communiqués of the IBGE. After analyzing the data, it was observed that the municipality of Catolé do Rocha had an average annual rainfall of 794,5 $\mathrm{mm}$ and that in ten years this sequence, the values were below in relation the average. The techniques and works to minimize the effect of evaporation of water sources and soil associated with surface water abstraction are ways for economic development and sustainable vision.

Keywords: water, economic development, sustainable vision.

\footnotetext{
*Autor para correspondência

Recebido para publicação em 21/08/2014; aprovado em 10/03/2015

${ }^{1}$ Graduado em Engenharia Agrícola, Universidade Federal de Campina Grande - UFCG. E-mail: gfilho@ hotmail.com

${ }^{2}$ Mestranda em Engenharia Agrícola, Irrigação e drenagem, Universidade Federal de Campina Grande - UFCG; e-mail:tainara.eng.agri@ gmail.com

${ }^{3}$ Mestrando em Engenharia Agrícola, Irrigação e drenagem Universidade Federal de Campina Grande - UFCG

${ }^{4}$ Graduado em Engenharia Agrícola, Universidade Federal de Campina Grande - UFCG
} 


\section{INTRODUÇÃO}

A região semiárida do nordeste lida periodicamente com chuvas irregulares em todo seu território, comprometendo o desenvolvimento da região. Nesse contexto, o aproveitamento dos recursos hídricos torna-se de suma importância para suprir as demandas do uso da água para humanos, animais, além dasatividades desenvolvidas na região.

A Política Nacional de Recursos Hídricos regulamentada pela Lei 9.433/97 representa o marco jurídico para a concepção de uma nova forma de pensar o aproveitamento dos recursos hídricos, passando de uma percepção retrograda para uma sustentável, desse bem tão precioso que é a água.

A região semiárida compreende uma área de $1.663 .200 \mathrm{~km}^{2}$, onde esta região ocupa $57,53 \%$ da área do nordeste brasileiro, com o predomínio do ecossistema caatinga, o solo em sua maioria é do tipo areno-argiloso, pobre em matéria orgânica. Além das dificuldades pedológicas da região, o regime de chuvas marcado pela irregularidade é um grave problema encontrado pelos sistemas de exploração da região (PADILHA et al., 2004).

Segundo Souza e Mota (1995), os escassos recursos hídricos de áreas semiáridas vêm sofrendo de forma acentuada o mau uso que lhe é imposto pelo homem, determinando assim, a ocorrência de problemas relativos à qualidade e disponibilidade de recursos hídricos que se encontram agravados pela intermitência de cursos d'água.

A água é o insumo básico da sobrevivência de todas as espécies e indicador do desenvolvimento de uma região, sendo necessária atenção especial no seu manejo visando sua conservação em qualidade e quantidade. Isso é alcançado por meio da gestão dos recursos hídricos, que se refere aos procedimentos relativos a tentativa de equacionar e resolver as questões da água e otimizar o seu uso (SETTI et al., 2001).

Objetivou-se avaliar o regime de chuvas no município de Catolé do Rocha, identificando se a precipitação pluviométrica é suficiente para suprir as necessidades da população e apresentandoas formas para um bom aproveitamento e manejo da água de chuva.

\section{MATERIAL E MÉTODOS}

A área em estudo está localizada no estado da Paraíba, mais precisamente, situado na mesorregião do sertão paraibano e na microrregião de Catolé do Rocha, contido na bacia hidrográfica do Médio Piranhas. De acordo com o IBGE (Instituto Brasileiro de Geografia e Estatística), no ano de 20102007 sua população era estimada em 28.759 habitantes. Área territorial de $552,112 \mathrm{~km}^{2}$. E encontra-se a 427 km da capital João Pessoa.

Figura 1. Mapa de localização do município de Catolé do Rocha no Estado da Paraíba, Brasil

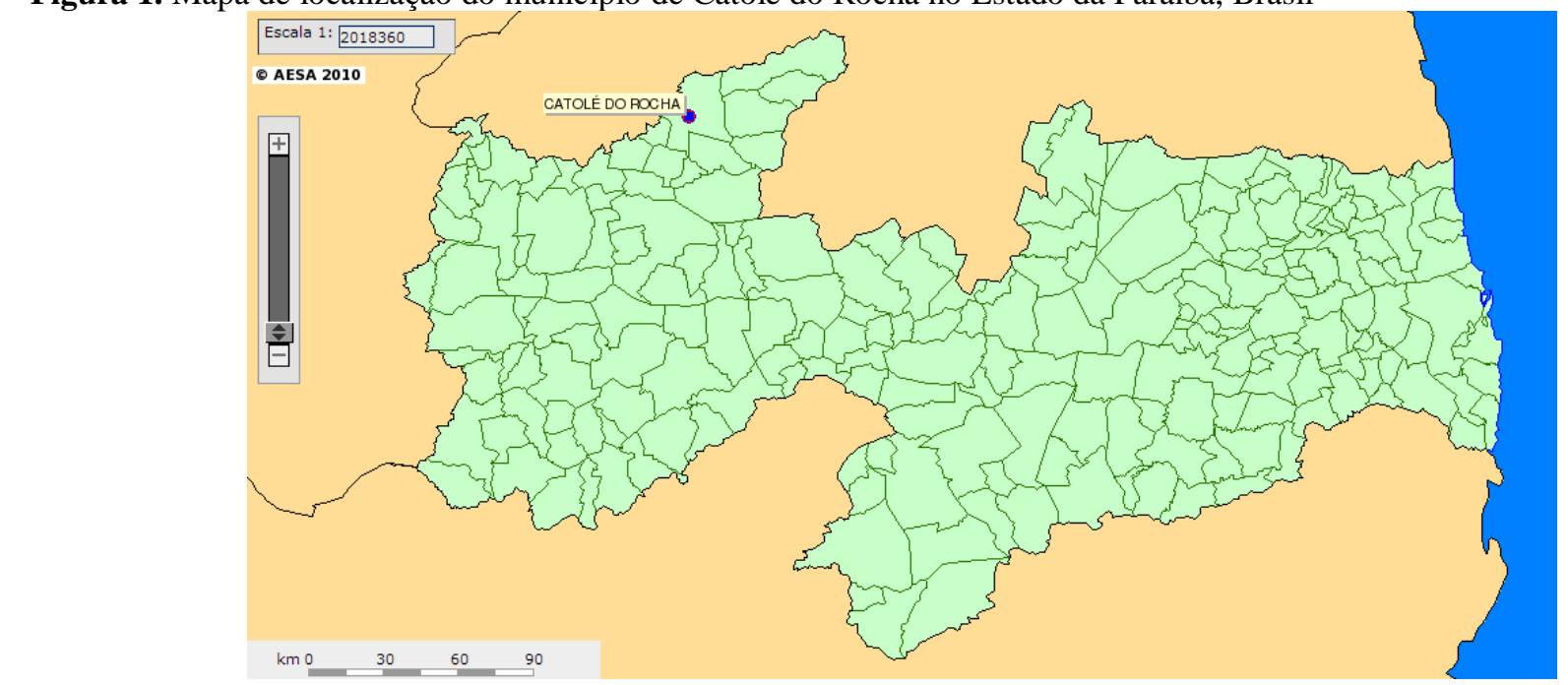

Fonte: SIGaesa-web (AESA)

O município de Catolé do Rocha encontra-se inserido nos domínios da bacia hidrográfica do Rio Piranhas, região do Médio Piranhas.Os principais cursos d' água são os riachos: Croata, Marcelino, Jenipapeiro, São José, dos porcos, Picos, Pilar, Santíssima, Capim Açu, São Pedro, Capim, Carnaubinha, Macaíba e o Córrego do Jenipapo. O principal corpo de acumulação é o açude Rabicho. Todos os cursos d' água têm regime de escoamento intermitente e o padrão de drenagem é o dendrítico.

O procedimento metodológico consistiu da análise de um banco de dadosreferentes aos últimos 17 anos, relacionados a precipitação do município de Catolé do Rocha, sendo estes dados oriundos da Agência Executiva de Gestão das Águas do Estado da Paraíba.

A partir dos dados observados foi possível realizar uma análise estatística descritiva com valores de média, mediana, coeficiente de variação, máximo e mínimo, além de confrontar as demandas de água necessárias para suprir as pessoas e animais de produção do local. Os dados estimados para consumo humano e animal, foram ajustados de vários comunicados técnicos do IBGE.

\section{RESULTADOS E DISCUSSÃO}

Mediante análise dos dados e conforme mapa de pluviometria média anual (AESA, 2012), onde este apresenta que o município de Catolé do Rocha encontra-se em uma zona de 800 mm/ano obteve-se os resultados da distribuição e demanda de água para a área em estudo. 
Distribuição temporal das chuvas mensais entre 1995 a 2011

Ao observar os dados mensais de chuvas (Tabela 1), percebe-se claramente as características de região semiárida, onde a falta de regularidade de chuvas durante o que é considerado meses chuvosos, realmente fica evidente, assim como recolher águas em janeiro na ordem de 330,2 no ano de 2000 não chega a ser usufruído pela agricultura, considerando que os meses subsequentes reduzem sensivelmente a contribuição de chuvas, tendo comprometido a produção para quem utiliza culturas de ciclos em torno de 90 dias. Com excesso ou déficit o efeito de incerteza para a exploração da agricultura de sequeiro exige que se tenha planejamento de técnicas e práticas de conservação de solo associado a captação de água para maior infiltração, permitindo assim, maior umidade para produzir em três a quatro meses as culturas básicas

Tabela 1. Valores de precipitação mensal numa série dos últimos dezessete anos no município de Catolé do Rocha no Estado da Paraíba. AESA. 2012

\begin{tabular}{|c|c|c|c|c|c|c|c|c|c|c|c|c|c|}
\hline Ano & Jan & Fev & Mar & Abr & Mai & Jun & Jul & Ago & Set & Out & Nov & Dez & anual \\
\hline 1996 & 94,6 & 110,0 & 127,4 & 599,0 & 130,1 & 18,3 & 30,8 & 14,8 & 0,0 & 0,0 & 8,0 & 12,0 & 1145,0 \\
\hline 1997 & 134,5 & 63,8 & 196,8 & 116,3 & 111,8 & 0,0 & 11,4 & 0,0 & 0,0 & 0,0 & 0,0 & 5,6 & 640,2 \\
\hline 1998 & 123,2 & 53,1 & 61,3 & 3,5 & 4,4 & 0,0 & 5,8 & 5,6 & 0,0 & 0,0 & 1,9 & 0,0 & 258,8 \\
\hline 1999 & 49,8 & 12,2 & 213,3 & 60,3 & 195,8 & 9,8 & 0,0 & 0,0 & 0,0 & 56,8 & 6,2 & 95,6 & 699,8 \\
\hline 2000 & 330,2 & 289,5 & 151,6 & 152,7 & 72,7 & 54,0 & 44,7 & 78,3 & 20,9 & 0,0 & 0,0 & 34,3 & 1228,9 \\
\hline 2001 & 25,5 & 16,9 & 124,7 & 94,3 & 52,2 & 88,2 & 17,7 & 0,0 & 0,0 & 12,6 & 64,4 & 19,4 & 515,9 \\
\hline 2002 & 301,3 & 105,6 & 252,6 & 227,4 & 100,4 & 58,5 & 17,0 & 0,0 & 0,0 & 0,0 & 16,5 & 2,5 & 1081,8 \\
\hline 2003 & 127,4 & 99,1 & 169,3 & 141,1 & 101,5 & 25,8 & 24,4 & 0,0 & 0,0 & 0,0 & 0,0 & 7,5 & 696,1 \\
\hline 2004 & 10,4 & 97,1 & 176,4 & 143,9 & 42,9 & & 70,4 & & 0,0 & 0,0 & 0,0 & 5,2 & 546,3 \\
\hline 2005 & 10,4 & 84,0 & 173,1 & 74,0 & 42,4 & 82,5 & 122,5 & 0,0 & 0,0 & 0,0 & 0,0 & 28,9 & 617,8 \\
\hline 2006 & 0,0 & 143,7 & 157,5 & 231,7 & 348,6 & 28,2 & 31,0 & 6,3 & 0,0 & 5,5 & 2,3 & 12,4 & 967,2 \\
\hline 2007 & 0,0 & 301,8 & 132,9 & 166,7 & 33,1 & 0,0 & 10,7 & 3,5 & 0,0 & 0,0 & 0,0 & 8,5 & 512,9 \\
\hline 2008 & 77,8 & 38,6 & 519,1 & 170,8 & 222,7 & 57,8 & 53,7 & 32,0 & 4,3 & 0,0 & 6,0 & 0,8 & 1183,6 \\
\hline 2009 & 116,8 & 133,0 & 101,8 & 225,6 & 266,8 & 153,9 & 121,7 & 62,3 & 0,0 & 0,0 & 0,0 & 70,6 & 1252,5 \\
\hline 2010 & 61,6 & 30,8 & 75,5 & 238,7 & 68,1 & 56,9 & 19,7 & 0,0 & 0,0 & 44,9 & 0,0 & 73,4 & 669,6 \\
\hline 2011 & 240,2 & 214,0 & 21,6 & 196,5 & 164,6 & 64,8 & 96,0 & 2,6 & 0,0 & 55,6 & 24,4 & 0,0 & 1080,3 \\
\hline 2012 & 79,9 & 157,5 & 126,4 & 42,7 & 0,0 & 0,0 & 3,5 & 0,0 & 0,0 & 0,0 & 0,0 & 0,0 & 410,0 \\
\hline CLIMAT & 104,9 & 114,7 & 163,6 & 169,7 & 115,2 & 43,7 & 40,1 & 12,8 & 1,5 & 10,3 & 7,6 & 22,2 & 794,5 \\
\hline
\end{tabular}

Distribuição anual das chuvas acumuladas anualmente entre 1996 a 2012

Após recolher dados mensais e anuais de uma série recente dos últimos 17 anos do município, observa-se que o mesmo apresenta uma precipitação média anual de 794,5mm, e que em dez anos desta sequencia, os valores apresentados foram inferior a média (Figura 2). A mediana foi de 696,1 $\mathrm{mm}$ ano-1, e que os anos que choveram acima de $800 \mathrm{~mm}$ por ano, foram os anos de 1996, 2000, 2002, 2006, 2008, 2009 e 2011, indicando que o município não vem atingindo a média estimada pela AESA (2012). Através da estatística descritiva podemos avaliar que o coeficiente de variação dos 17 anos, foi de $39 \%$, indicando uma variabilidade elevada, exigindo mais ação no planejamento de acolher águas, pois embora pareça um município com um bom índice pluviométrico médio, a realidade dos últimos anos, indica que muitas obras de captação de água de chuva devem ocorrer e com critérios de construção de acordo com o conhecimento prévio das características locais, isto é, evaporação elevada, escoamento alto, riachos com níveis de sais elevados, e tantos outros que exigem escolher adequadamente de acordo com o local da comunidade.

Figura 2: Histograma das precipitações médias anuaisdo municipio de Catolé do Rocha no Estado da Paraíba, Brasil

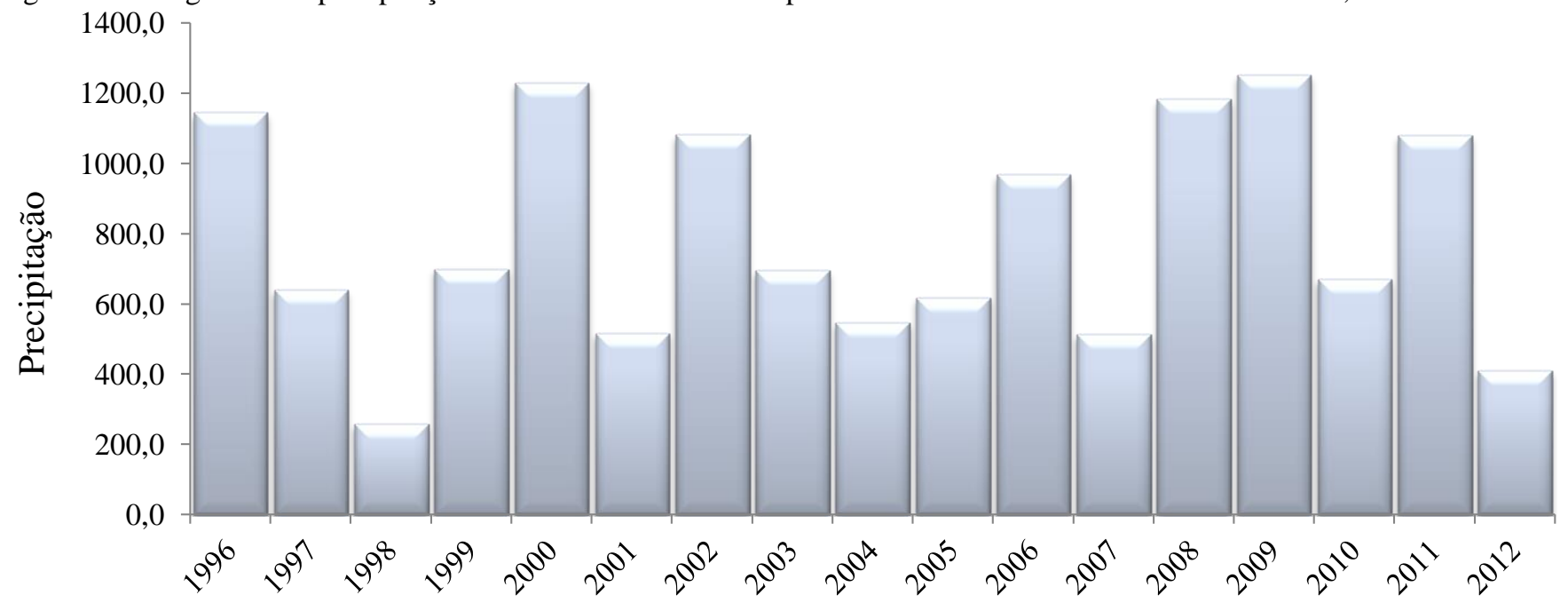

Fonte: AESA, 2012 


\section{Demanda de consumo de água no município}

Quando se estima a necessidade das pessoas e dos animais no consumo de água (Tabela 2) e avalia-se o quando de água é precipitado no espaço geopolítico do município de Catolé do Rocha $\left(552 \mathrm{Km}^{2}\right)$ obtêm-se alguns volumes decorrentes do acúmulo de chuvas anuais (Tabela 1) e encontram-se os seguintes valores: em relação a média precipitada na série histórica de 17 anos, obtêm-se 438.652.984 $\mathrm{m}^{3}$ ano $^{-1}$ ( 794,5 mm ano $\left.{ }^{-1}\right)$, o mínimo precipitado para a mesma série, foi de $142.886 .585,6 \mathrm{~m}^{3}$ ano ${ }^{1}\left(258,8 \mathrm{~mm} \mathrm{ano}^{-1}\right)$ e o máximo no município para o mesmo período de análise, foi de $691.520 .280 \mathrm{~m}^{3}$ ano $^{-1}(1.252,5 \mathrm{~mm}$ $\left.\mathrm{ano}^{-1}\right)$. Portanto, as políticas públicas de gestão de água para o município, teriam que avaliar o potencial existente de fontes de águas e a referida distância das comunidades, principalmente da zona rural e planejar a captação de água que pudesse oferecer volume de água para seus habitantes, de forma que se a análise fosse baseada na média da série histórica de 17 anos, o compromisso seria de reservar água na ordem de $1 \%$ do que chove, já para o mínimo de chuva registrada (ano de 1998), a demanda de reserva seria em torno de $2,5 \%$ e quando comparado ao ano que registrou o máximo de precipitação (2009), a demanda diminuiria para aproximadamente $0,6 \%$ do que precipitou.

Tabela 2. Quadro de demanda de água para dessedentação animal e consumo humano para o município de Catolé do Rocha no Estado da Paraíba, Brasil

\begin{tabular}{cccccc}
\hline $\begin{array}{c}\text { Catolé do Rocha 2010 e } \\
\text { pecuária 2011 (IBGE 2012) }\end{array}$ & Quant & Unid. & $\begin{array}{c}\text { Demanda/Consumo } \\
\text { em litros por dia }\end{array}$ & $\begin{array}{c}\text { Consumo em } \\
\mathbf{m}^{\mathbf{3} p o r} \text { dia }\end{array}$ & $\mathbf{m}^{\mathbf{3}}$ por ano \\
\hline População Estimada 2010 & 28.759 & habitantes & 150 & $4.313,85$ & $1.574 .555,25$ \\
\hline Bovinos & 15.101 & cabeças & 45 & 679,55 & $248.033,93$ \\
Equinos & 458 & cabeças & 30 & 13,74 & $5.015,10$ \\
Asininos & 111 & cabeças & 15 & 1,67 & 607,73 \\
Muares & 192 & cabeças & 15 & 2,88 & $1.051,20$ \\
Caprinos & 764 & cabeças & 7 & 5,35 & $1.952,02$ \\
Ovinos & 3.484 & cabeças & 7 & 24,39 & $8.901,62$ \\
Suínos & 689 & cabeças & 7 & 4,82 & $1.760,40$ \\
Galinhas & 6.331 & cabeças & 2 & 12,66 & $4.621,63$ \\
Galos, frangas, frangos e pintos & 4.522 & cabeças & 2 & 9,04 & $3.301,06$ \\
Vacas ordenhadas & 3.883 & cabeças & 50 & 194,15 & $70.864,75$ \\
\hline \multicolumn{7}{c}{ Total de necessidade de água } & & $\mathbf{5 . 2 6 2 , 1 0}$ & $\mathbf{1 . 9 2 0 . 6 6 4 , 6 8}$ \\
\hline
\end{tabular}

Em todas as avaliações (mínima, média ou máxima), o importante é não deixar no planejamento hídrico do município, um levantamento da população de forma a mensurar espacialmente esta demanda, e verificar "in loco" todas as condições propicias para construções que acumulem água das chuvas, evitando as perdas por escoamento durante o processo de chuvas, ou mesmo o efeito de evaporação elevada durante $o$ armazenamento das águas. Para associar este planejamento, promover técnicas de maior infiltração de água, que auxilia em prolongar maior tempo de umidade o que produz maior chance de sucesso na produção agrícola de sequeiro.

\section{CONCLUSÕES}

Aprecipitação do município possui períodos críticos onde as chuvas são abaixo da média esperada assim deve-se utilizar técnicas de contenção de água e conservação do solo, para manter a sustentabilidade da região.

Técnicas e obras que minimizem o efeito de evaporação dos mananciais e solo, associado a captações de água superficiais que evitem perdas de escoamento em momentos de enxurradas.

Utilização de barragens subterrâneas que propiciam a exploração agrícola em sua bacia hidráulica.

Obras de obstáculos superficiais, também são técnicas eficazes para a contenção de água e solo, em regiões onde ocorrem intensas chuvas em curto tempo.

\section{REFERENCIAS}

AESA - Agência Executiva de Gestão das Águas do Estado da Paraíba. Previsão do Tempo - chuvas. Disponível em: http://www.aesa.pb.gov.br. Acesso em 09 de maio de 2012.

IBGE - Instituto Brasileiro de geografia e Estatística. Cidades. Disponível em: http://cidades.ibge.gov.br/xtras/perfil.php?lang=\&codmun=25 0430. Acesso em: 12 de maio de 2012.

PADILHA, J. A.; ZANGHETIN, M. F. L.; ORTEGA, E. O Uso da Água nas Micro-Bacias Hidrográficas do Semi-Árido do Nordeste Brasileiro e o Conceito Base Zero. Proceedings of IV Biennial International Workshop "Advances in Energy Studies". Unicamp, Campinas, SP, Brazil. June 16-19, 2004. Pag. 65-72.

SETTI, A. A.; LIMA, J. E. F. W.; CHAVES, A. G. M.; PEREIRA, I. C. AGÊNCIA NACIONAL DE ENERGIA ELÉTRICA; AGÊNCIA NACIONAL DE ÁGUAS (ANA). Introdução ao Gerenciamento de Recursos Hídricos. $2^{\mathrm{a}}$ ed. Brasília, 328 p. 2001.

SOUZA, R. O.; MOTA, F. S. Qualidade e conservação da água com vistas ao desenvolvimento sustentável no semiárido Nordestino. Brasília, Projeto Áridas, 1995. 70p. GT II Recursos Hídricos. 